\title{
One drug to treat them all: ethical implications of the MORDOR trial of mass antibiotic administration to reduce child mortality
}

\section{Clarence C Tam ${ }^{1,2}$, Vittoria Offeddu' ${ }^{1}$, Jane Mingjie Lim ${ }^{1}$, Teck Chuan Voo ${ }^{3}$}

\footnotetext{
${ }^{1}$ Saw Swee Hock School of Public Health, National University of Singapore and National University Health System, Singapore

${ }^{2}$ London School of Hygiene \& Tropical Medicine, London, United Kingdom

${ }^{3}$ Centre for Biomedical Ethics, Yong Loo Lin School of Medicine, National University of Singapore and National University Health System, Singapore
}

Mass azithromycin administration to reduce allcause mortality in children raises important issues related to rational antibiotic use, because health gains achieved through mass antibiotic administration could be offset by potential adverse consequences of increased antibiotic resistance.
1 he recent Macrolides Oraux pour Réduire les Décès avec un Oeil sur la Résistance (MORDOR) cluster-randomised trial of mass azithromycin administration in Malawi, Niger and Tanzania demonstrated a $13.5 \%$ overall reduction in under-5 childhood mortality among communities receiving twice-yearly azithromycin [1]. Subgroup analyses suggested that these mortality reductions were consistent only in children $<6$ months, and that overall results were mainly driven by mortality reductions in Niger, where both mortality and mortality reductions were considerably greater than in the other two countries. Uncertainty in effect estimates from Malawi and Tanzania was high, because baseline mortality in these two countries was much lower than assumed in the trial design.

Further evidence will be needed to determine whether this is a generalisable finding and how much of an impact mass azithromycin administration can have on infant mortality. However, at a time of concerted efforts to integrate reductions in both infant mortality and antimicrobial resistance as part of the Sustainable Development Goals, this trial highlights the need to deal with complex dilemmas in global health, and raises important ethical issues about rational antibiotic use. As the authors of the trial point out, any use of mass antibiotic treatment in this way would need consideration of the potential adverse effects of administering azithromycin to young children. These could result from both adverse drug reactions and selection of antibiotic-resistant bacterial strains that could have subsequent clinical implications. Additionally, in public health terms non-maleficence considerations would extend to potential harms not just to azithromycin recipients, but also to wider society. These could include the potential transmission of antibiotic-resistant bacterial strains to others, as well as diminished effectiveness of azithromycin for treating infections caused by these resistant bacteria. The MORDOR trial did not identify serious adverse events attributable to azithromycin among recipients. The trial authors did not specifically report changes in antibiotic resistance in bacterial species in the study population (this work is ongoing), although previous studies have reported increases in carriage of macrolide-resistant Streptococcus pneumoniae and Escherichia coli in children following mass azithromycin administration for trachoma control 
[2-6]. Thus, although there is good reason to believe that mass azithromycin treatment would lead to increased levels of bacterial resistance, the clinical implications and public health impact are currently unknown.

Mass administration of azithromycin is recommended by the World Health Organization (WHO) as part of strategies to eradicate both trachoma and yaws $[7,8]$. The findings of the MORDOR trial could provide a rationale for extending mass azithromycin administration to other settings without endemic trachoma and yaws, as an intervention to reduce general childhood mortality. In many settings where mass antibiotic administration to reduce childhood mortality might be used, general access to antibiotics to treat infections may be limited because of lack of health care infrastructure or resources. Conversely, in many regions of the world over-use and misuse of antibiotics with no clear clinical benefit is common. It could be argued that such inequities in antibiotic access provide reasons to favour use of mass administration to reduce childhood mortality on the basis of social justice. We do not find such arguments convincing, however, as sub-optimal use of antibiotics in one context, whether through over-use or lack of access, cannot be used to justify its questionable use in other contexts. Considerations of equity must be weighed up against issues of beneficence and harm. This raises a fundamental question:

"Given a proven preventive effect of mass azithromycin administration on childhood mortality, what is the moral obligation to provide such treatment (or what are the ethical implications of withholding such treatment)?"

From a global health ethics viewpoint, various perspectives could be used to consider the moral grounds of an obligation to benefit children by means of mass antibiotic treatment $[9,10]$. We focus on two key perspectives: humanitarianism and human rights. These are often linked in practice but are conceptually distinct. Global health initiatives such as the Global Fund to Fight AIDS, Tuberculosis and Malaria and Gavi, the Vaccine Alliance, are underpinned by a humanitarian perspective [11-13]. Some of the global elimination programmes rely on drug donations, including azithromycin for trachoma control (under The International Trachoma Initiative). At face value, humanitarianism could also be seen as a basis for provision of the same antibiotic en masse to prevent childhood mortality. However, what makes a humanitarian perspective less compelling in this context is that there is no duty of easy rescue: while lives might be saved by this intervention, we might be sacrificing something of comparable moral importance in the form of future disease burden and mortality from increases in antimicrobial resistance.

From a rights perspective, it seems intuitive to consider the extension of life (or the avoidance of preventable death) to be a basic moral and human right. However, this stance in itself does not determine by what specific means this right should be protected. Many childhood interventions are not implemented in certain settings despite proven benefit. Examples include certain vaccines that are under-used because they are considered too costly, because of competing health priorities, or because of technical challenges in implementation. High cost of vaccine and vaccine delivery, for example, are major factors in the slow implementation of sustainable immunisation programmes against rotavirus [14] and human papillomavirus $[15,16]$. Vaccines against typhoid in have been recommended by WHO for endemic and epidemic settings for over 10 years, but widespread implementation in many settings is hampered by the need to fund other vaccination programmes, as well as lack of specific diagnostic and surveillance infrastructure to monitor disease burden and assess potential vaccine impact [17].

However, a number of key international documents support a human rights argument for mass antibiotic treatment to prevent childhood mortality. The Sustainable Development Goals include targets "to reduce neonatal mortality to at least as low as 12 per 1,000 live births and under-5 mortality to at least as low as 25 per 1,000 live birth" by 2030. Although these are aspirational targets, they resonate strongly with the international human rights system or framework. Strictly speaking, 'human rights' refer to rights stipulated in

Using a global health ethics perspective, and contingent on the proven effectiveness of mass antibiotic administration, we find strong human rights arguments in favour of its use as an intervention to reduce child mortality. However, we argue on the basis of the precautionary principle and the principle of self-determination that its implementation is justifiable only with adequate investment in measures to monitor adverse effects and to reduce long-term reliance on its use, including sanitation and healthcare. 


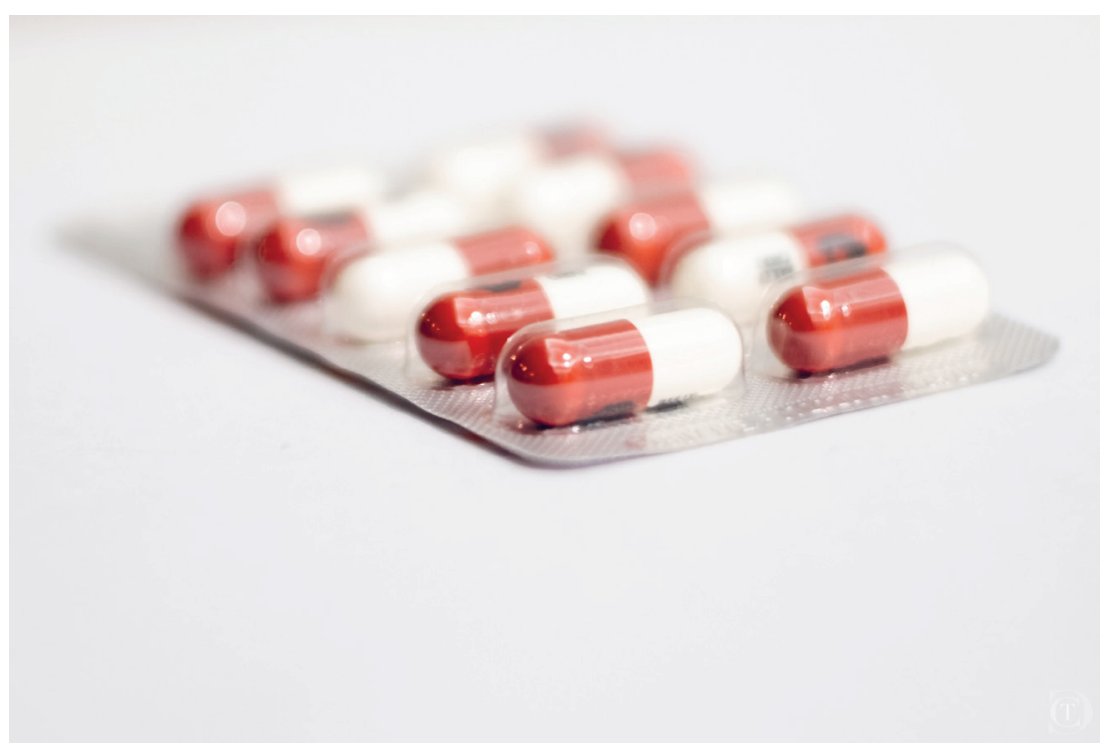

Photo: from the collection of Dr Clarence C Tam (used with permission) the Universal Declaration of Human Rights and in human rights treaties such as the International Covenant on Economic, Social, and Cultural Rights (ICESCR). The latter are legally binding on states that have signed and ratified them [18] and may be legally protected and enforced through national constitutions and law [19]. Article 12 of the ICESCR states that "The States Parties... recognize the right of everyone to the enjoyment of the highest attainable standard of physical and mental health", and that steps to be taken progressively (in recognition of resource constraints) to "achieve the full realization of this right shall include those necessary [...] for the reduction of [...] infant mortality and for the healthy development of the child" [20]. Article 6 of The United Nations Convention on the Rights of the Child [21] spells out every child's inherent right to life and the duty of states to ensure to the maximum extent possible their survival and development. More specifically, Article 24 includes the following relevant provisions:

a) To diminish infant and child mortality;

b) To ensure the provision of necessary medical assistance and health care to all children with emphasis on the development of primary health care;

c) To combat disease and malnutrition, including within the framework of primary health care, through, inter alia, the application of readily available technology and through the provision of adequate nutritious foods and clean drinking-water, taking into consideration the dangers and risks of environmental pollution

To the extent that mass antibiotic administration is a readily available technology that turns out to have a scientifically demonstrable effect in preventing childhood mortality, the international human rights framework seems to confer at least a prima facie duty to provide children access to that technology.

The translation of international treaty obligations into rights-based public health programmes should, however, include mechanisms for monitoring and assuring equitable access as well as transparency and accountability, with emphasis on protecting the rights of the most vulnerable and disadvantaged [22,23]. If mass antibiotic treatment for mortality prevention is indeed an obligation correlative to respecting the rights of children, then the question remains of how to deal with the potential adverse consequences.

Here we view the precautionary principle to be particularly pertinent. The precautionary principle asserts that given the potential for serious harm to humans or the environment from a given activity, the burden of proof rests on assuring the safety of the activity, and that preventive measures to mitigate potentially harmful effects of the activity should not be delayed even if uncertainty exists about the probability, severity, remediability or reversibility of harm from the activity. Although commonly used to mitigate potential harms from industry or government activity, particularly in the area of environmental pollution, the precautionary principle applies equally to public health interventions [24]. The UN Declaration on Antimicrobial Resistance recognises that "within the broader context of antimicrobial resistance, resistance to antibiotics [...] is the greatest and most urgent global risk, requiring increased attention and coherence at the international, national and regional levels" [25]. In this context, the potential for mass antibiotic administration to drive the emergence and spread of antibiotic resistance constitutes a serious, but uncertain threat to human health. Potential harms from mass antibiotic administration could include future reversals in mortality reduction resulting from increased antibiotic resistance, potential harms to others (including other species) from spread of antibiotic-resistant bacteria, and environmental contamination with antibiotic residues that could drive further resistance. Further, certain antibiotics may be critical medicines in the treatment of specific infections, and this crucial role should be protected - azithromycin, for example, is a key treatment for gonorrhoea. Additionally, the key role that azithromycin plays in health care is un- 
derlined by its inclusion in the World Health Organization's Essential Medicines list for the treatment of genital tract infections and trachoma [26].

The precautionary principle asserts that preventive measures should be put in place to mitigate these potential harms. In our view these include mechanisms to monitor and assure the safety of mass antibiotic administration, both in terms of adverse drug reactions and emergence of antibiotic resistance, as well as measures to reduce dependence on mass antibiotic administration, including improvements in sanitation, water quality, immunisation coverage and provision of adequate health care. In addition, these measures should be in place and have the capacity to assure safety from the outset, as the burden of proof must rest on assuring the safety of a planned activity, rather than demonstrating substantial harm from an established activity [24].

We argue that any future implementation of mass azithromycin administration to reduce mortality through as yet undetermined mechanisms should only occur alongside adequate implementation of surveillance mechanisms to monitor adverse drug reactions as well as emergence of antibiotic resistance, with a clear framework for deciding if and when this intervention does not satisfy acceptable levels of safety. In addition, such implementation should occur alongside investment in sanitation and health care infrastructure to reduce reliance on mass antibiotic administration in these communities. Such an implementation recognises that the burden of proof may change over time with accumulating evidence of benefits and externalities. In addition, investment in monitoring systems and alternative infrastructure respects the principle of self-determination, providing communities with increased autonomy to make informed decisions about whether continued dependence on mass antibiotic administration is acceptable. Without such infrastructure in place, the only measurable outcome is mortality, which at least in the short-term always favours mass antibiotic administration. Ensuring the capacity to measure the benefits of mass administration relative to other interventions, and weigh up its benefits against measurable harms, provides the means to make more informed and sustainable policy choices.

The potential to prevent childhood mortality with a single pill - the one drug to treat them all - is a tempting prospect. The road to MORDOR, however, is fraught with pitfalls. A global ethics perspective, though often overlooked, highlights the complex challenges posed by antimicrobial resistance and the need for integrated, cross-sectoral approaches to infectious disease control, global antimicrobial stewardship, sanitation and universal health care, while providing a framework for action that respects the rights of both individuals and the global community.

Acknowledgements: This publication was supported by the Antimicrobial Resistance program of the Saw Swee Hock School of Public Health, National University of Singapore.

Funding: None.

Authorship contributions: CCT conceived the idea for the manuscript and drafted the paper. All authors contributed to the development of arguments presented in the paper and made substantive comments on all versions of the draft.

Competing interests: The authors have completed the Unified Competing Interest form at www.icmje.org/coi_ disclosure.pdf (available on request from the corresponding author) and declare no conflict of interest).

1 Keenan JD, Bailey RL, West SK, Arzika AM, Hart J, Weaver J, et al. Azithromycin to Reduce Childhood Mortality in Sub-Saharan Africa. N Engl J Med. 2018;378:1583-92. Medline:29694816 doi:10.1056/NEJMoal715474

2 Leach AJ, Shelby-James TM, Mayo M, Gratten M, Laming AC, Currie BJ, et al. A prospective study of the impact of community-based azithromycin treatment of trachoma on carriage and resistance of Streptococcus pneumoniae. Clin Infect Dis. 1997;24:356-62. Medline:9114185 doi:10.1093/clinids/24.3.356

3 Skalet AH, Cevallos V, Ayele B, Gebre T, Zhou Z, Jorgensen JH, et al. Antibiotic selection pressure and macrolide resistance in nasopharyngeal Streptococcus pneumoniae: a cluster-randomized clinical trial. PLoS Med. 2010;7:e1000377. Medline:21179434 doi:10.1371/journal.pmed.1000377

4 Coles CL, Seidman JC, Levens J, Mkocha H, Munoz B, West S. Association of mass treatment with azithromycin in trachoma-endemic communities with short-term reduced risk of diarrhea in young children. Am J Trop Med Hyg. 2011;85:691-6. Medline:21976574 doi:10.4269/ajtmh.2011.11-0046

5 Ho DK-H, Sawicki C, Grassly N. Antibiotic Resistance in Streptococcus pneumoniae after Azithromycin Distribution for Trachoma. J Trop Med. 2015;2015: 917370. Medline:26557143 doi:10.1155/2015/917370 
6 Seidman JC, Johnson LB, Levens J, Mkocha H, Muńoz B, Silbergeld EK, et al. Longitudinal comparison of antibiotic resistance in diarrheagenic and non-pathogenic escherichia coli from young Tanzanian Children. Front Microbiol. 2016;7:1420. Medline:27656179 doi:10.3389/fmicb.2016.01420

7 World Health Organization. Trachoma- Key Facts. 2018. URL: http://www.who.int/en/news-room/fact-sheets/detail/trachoma. Accessed: 25 September 2018.

8 World Health Organization Department of Control of Neglected Tropical Diseases. Eradication of yaws-the Morges strategy. In: Releve epidemiologique hebdomadaire. 18 May 2012. Available: http://www.ncbi.nlm.nih.gov/pubmed/24340400. Accessed: 25 September 2018.

9 Millum J, Emanuel EJ. Global justice and bioethics. Oxford University Press; 2012.

10 Benatar SR, Brock G. Global Health and Global Health Ethics. Cambridge: Cambridge University Press; 2011.

11 World Health Organization. Global Health Initiatives. (accessed 25 Sep 2018). Available: http://www.wpro.who.int/entity/country_focus/global_health_initiatives/en/. Accessed: 25 September 2018.

12 World Health Organization. Aid for health. Available: http://www.who.int/hdp/aid/en/. Accessed: 25 September 2018.

13 Muraskin WA. Crusade to immunize the world's children : the origins of the Bill and Melinda Gates children's vaccine program and the birth of the Global Alliance for Vaccines and Immunization. Los Angeles: Global BioBusinessBooks; 2005.

14 Lo Vecchio A, Liguoro I, Dias JA, Berkley JA, Boey C, Cohen MB, et al. Rotavirus immunization: Global coverage and local barriers for implementation. Vaccine. 2017;35:1637-44. Medline:28216189 doi:10.1016/j.vaccine.2017.01.082

15 Bruni L, Diaz M, Barrionuevo-Rosas L, Herrero R, Bray F, Bosch FX, et al. Global estimates of human papillomavirus vaccination coverage by region and income level: a pooled analysis. Lancet Glob Health.2016;4:e453-63.

16 World Health Organization. Scaling up HPV vaccine introduction. 2018. Available: http://apps.who.int/iris/bitstream/ha ndle/10665/251909/9789241511544-eng.pdf?sequence=1. Accessed: 25 September 2018.

17 World Health Organization. Feedback from the regions and countries on the implementation of SAGE recommendations on typhoid vaccines. 2010. Available: http://www.who.int/immunization/sage/1_Report_to_SAGE_on_typhoid_activities_260ct10.pdf. Accessed: Accessed: 25 September 2018.

18 Macklin R. Respecting, protecting, and fulfiling human rights. Double standards in medical research in developing countries. Cambridge: Cambridge University Press; 2004.

19 Hogerzeil HV, Samson M, Casanovas JV, Rahmani-Ocora L. Is access to essential medicines as part of the fulfilment of the right to health enforceable through the courts? Lancet. 2006;368:305-11. Medline:16860700 doi:10.1016/S01406736(06)69076-4

20 Office of the United Nations High Commissioner for Human Rights. International Covenant on Economic, Social and Cultural Rights. 1966. Available: https://www.ohchr.org/en/professionalinterest/pages/cescr.aspx. Accessed: 25 September 2018 .

21 United Nations Convention on the rights of the child. In: New York. 1989. Available: https://reaties.un.org/doc/Treaties/1990/09/1990090203-14 AM/Ch_IV_11p.pdf. Accessed: 30 May 2018.

22 Hogerzeil HV. Essential medicines and human rights: what can they learn from each other? Bull World Health Organ. 2006;84:371-5. Medline:16710546 doi:10.2471/BLT.06.031153

23 Schrecker T, Chapman AR, Labonté R, De Vogli R. Advancing health equity in the global marketplace: How human rights can help. Soc Sci Med. 2010;71:1520-6. Medline:20822839 doi:10.1016/j.socscimed.2010.06.042

24 Goldstein BD. The precautionary principle also applies to public health actions. Am J Public Health. 2001;91:1358-61. Medline:11527755 doi:10.2105/AJPH.91.9.1358

25 Draft political declaration of the high-level meeting of the General Assembly on antimicrobial resistance. 2016. Available: https://www.un.org/pga/71/wp-content/uploads/sites/40/2016/09/DGACM_GAEAD_ESCAB-AMR-Draft-Political-Declaration-1616108E.pdf. Accessed: 28 May 2018.

26 World Health Organization. WHO Model List of Essential Medicines. 20th edition. 2017. Available: http://www.who. int/medicines/publications/essentialmedicines/20th_EML2017_FINAL_amendedAug2017.pdf?ua=1. Accessed: 28 May 2018.

\author{
Correspondence to: \\ Clarence C Tam \\ Saw Swee Hock School of Public Health \\ National University of Singapore \\ Tahir Foundation Building (MD1) \\ 12 Science Drive 2 \\ Singapore 117549 \\ Clarence.tam@nus.edu.sg
}

